\title{
Planned extraction of first permanent molars during late childhood: A clinical note and mini-review
}

\author{
ElSheikh $\mathrm{M}^{1 *}$ and Ali $\mathrm{A}^{2}$ \\ ${ }^{1}$ Private practice, Sanonaw Dental Surgery Center, Taballino, Benghazi, Libya \\ ${ }^{2}$ Department of Pediatric Dentistry, University of Garyounis, Benghazi, Libya
}

\begin{abstract}
Background: In patients with mixed dentitions, the extraction of one or more first permanent molars should be considered as part of an orthodontic treatment plan while taking into account different patterns of malocclusions.

Aims: The purpose of this mini-review is to give young dental practitioners the best advice on appropriate treatment of grossly carious first permanent molars for child patients, particularly where the patient may never be expected to consult an orthodontist.

Conclusion: If extraction of first permanent molars in children is done without proper planning, orthodontists might be faced with the adverse consequences arising from defective development of occlusion which would result from uncontrolled first molar extraction. Due to the unique nature of every child patient, it is impossible to follow a treatment protocol that will suit all situations. Control or prevention of dental caries in newly erupted first permanent molars will greatly reduce the many dilemmas in the clinical management of gross caries. The best advice on management is based on experience of being confronted with such problems.
\end{abstract}

\section{Clinical scenario}

Patients with mixed dentitions where extraction of one or more first permanent molars is considered as part of an orthodontic treatment plan, while taking into account different patterns of malocclusions.

\section{Introduction}

Young dental practitioners frequently seek advice on appropriate treatment for grossly carious first permanent molars for child patients, particularly where the patient may never be expected to consult an orthodontist. Orthodontists are frequently faced with the probable development of malocclusion due to uncontrolled extraction of first permanent molars in children. Applying preventive measures of dental caries in newly erupted first permanent molars would greatly save those teeth and thus help the practitioner avoid many dilemmas in the clinical management of gross carious lesions which may render the teeth not restorable [1]. This mini-review is an analysis coupled with advice on management, which is based on personal experiences of being confronted with such problems.

In general, many current restorative techniques fail to help the child patient to conserve their badly decayed first permanent molars. For example, extraction of first molars affected with severe molar incisor hypomineralization $(\mathrm{MIH})$ has been suggested to be a good treatment modality [2]. Large amalgam and composite restorations of heavily carious first permanent molars generally have limited life and need to be replaced within 5-10 years because of the possibility of secondary caries. The second cavity preparation will need to be larger than the first due to the necessity to remove more carious structure, and this undoubtedly weakens the remaining tooth substance and thus threatens the life of the molar's pulp. A significant restricted life of the molar can be attributed mostly to failure of the coronal restoration unless the child's oral health care is exceptionally good. The life of a tooth depends on the quality of the restoration and any associated endodontic treatment and crowns. Besides, endodontic treatment of molar teeth has a relatively high failure rate; which usually increases the later risk of tooth loss, perhaps by a five- year time postoperatively [35]. In addition, it should be considered well if the child should receive a prosthetic appliance, which in some situations is not appropriate because they exacerbate the poor oral condition especially if the child does not show cooperation to the oral hygiene instructions.

Because extraction of badly decayed first molars is generally the choice of treatment; the timing and consequences of this last-resort practice is important [6]. What will be done should be based on adequate diagnosis and case analysis before the extraction.

However, before extraction it is necessary to check the following:

a) Is the patient in pain because of molar pulp exposure?

b) What is the parents' attitude about dental treatment of their child? What is the likelihood of regular follow-up for their child patient?

c) What is the general condition of each first permanent molar? How many molars are affected by dental caries? How severe is the dental caries problem, or how large is the restoration, if present?

d) Is there any malocclusion and in case there is, what type, e.g. Class I, Class II Division 1, Class II Division 2 or Class III?

Correspondence to: Moaaz M. Elsheikh, Sanonaw Dental Surgery Center Tablino. Benghazi, Libya, Tel: +20110951801; E-mail: moaazelsheikh@yahoo.com

Key words: dental practice, extraction, orthodontic treatment

Received: May 03, 2015; Accepted: June 23, 2015; Published: June 27, 2015 
e) Is the malocclusion partly a skeletal problem?

f) Is there any anterior crowding? Is there a primary space deficiency, as distinct from space loss?

g) Is there sufficient space for eruption of canines and first and second premolars? Has there been space loss because of gross proximal caries or loss of primary molars?

h) What is the stage of dental development? How many months or years before eruption of mandibular and maxillary second permanent molars?

i) Is there congenital absence of any teeth, such as second premolars, or third molars? (It is difficult to assess without radiographs). In this regard, it has been reported that third molars tend to develop earlier when the first molars, on the same side, have been extracted [7]. If third molars are partially impacted due to loss of space, then extraction of hopeless first molar carries another advantage of providing space [8] or correcting their malposition [9].

j) What are the positions of mandibular and maxillary second permanent molars? Is there ectopic position or impaction at the distal of the carious first molar?

k) Are there any oral functions, or parafunctional habits, that may be of significance?

\section{Requirement for clinician}

An experienced clinician should have the ability to predict and compare the likely effects of "controlled" versus "uncontrolled extraction" of first permanent molars during the mixed dentition stage of dental development. It is essential that the clinician have a broad knowledge about dental development in order to predict, with reasonable certainty, the timing and direction of tooth eruption, and how teeth are likely to drift or change their position after they have erupted. Such a prediction also requires knowledge of the forces of the oral environment which controls the position of teeth. These environmental force conditions include:

a) Eruptive force, related to the axial direction of tooth which indicates its path of eruption.

b) Normal oral functional forces of chewing, swallowing, facial expression (lips) which act on the crowns of the teeth and help to control their positions. If a tooth is lost in the dental arch, then adjacent teeth lose proximal and occlusal functional support and may tip toward any adjacent extraction space. Also, a tooth which is already tipped mesially or distally along the arch will tip even more if there is an adjacent extraction space.

c) Abnormal habits, such as sucking, swallowing, biting and heavy chewing (including clenching and bruxism) will produce abnormal movement of teeth.

\section{Extraction of the maxillary first permanent molar}

a) Uncontrolled extraction: the second molar will take the place of first molar, without having any effect on the positions of the anterior permanent teeth, i.e., incisors will not change even if they were crowded or proclined, in which case it will be difficult to correct anterior malocclusion, unless the first molar extraction space is temporarily saved. In such a situation, interim-space maintenance has been described [10].

b) Controlled extraction: endeavoring to delay extraction of first molar until closer to the time of, or possibly after, the eruption of second molar, should serve a natural form of space maintainer.

Temporary saving of grossly carious first permanent molars during the mixed dentition stage of development can enable the use of $2 \times 4$ fixed appliances to correct some problems of anterior malocclusion, such as protrusion and crowding. Also if there is a forward drift of the molar(s) blocking out the space for premolars or canines, temporary retention of the first molars can provide space for later correction of buccal segment crowding by first molar extraction after eruption of second molars.

In order to postpone the loss of molars if there is large cavitation with possible pulp involvement, request temporary conservation of first permanent molar with pulp mummification, or pulp capping with mineral trioxide aggregate (MTA) or calcium hydroxide paste [1115 ] in order to reduce invasiveness of restorative procedures and to minimize costs to the patient/parent.

When extraction of molars is planned, there would be no benefit to the patient in providing full endodontic treatment with or without coronal restoration such as with a stainless steel crown (an additional financial cost). Glassionomer cement restoration following atraumatic restorative treatment (ART) [16] procedure (instead of temporary stainless steel crowns, which require more invasive and costly procedures) should provide sufficient temporary conservation of the affected molar.

If there is no anterior malposition of teeth or malocclusion, there would be less need to delay maxillary molar extraction. Extraction of maxillary first molars alone, in the absence of significant defects in mandibular first molars, will result in Class II molar occlusion (mandibular first molar to maxillary second molar) which is clinically acceptable.

\section{Extraction of the mandibular first permanent molar}

a) Uncontrolled extraction: there is good expectation that the second permanent molar will drift with mesial tipping. This drift may or may not compromise anterior space requirements, but does produce space problems which are less likely than with immediate extraction of maxillary first permanent molars.

An exception to such mesial drift might occur if unerupted second premolar is orientated distally, in which case the premolar may erupt distally (more likely when the primary molar predecessor is missing) so as to restrict the mesial drift of the mandibular second permanent molar.

b) Controlled extraction: immediate extraction of the mandibular first permanent molar probably has no adverse effects as far as future development of the occlusion (including orthodontic intervention) and masticatory efficacy, are concerned. No form of space maintenance should be needed, but a regular check-up should be monitored.

Therefore, extraction of the mandibular first permanent molar in the dental age range from 7-10 years is unlikely to create special problems for any later orthodontic treatment. Halicioglu et al. have mentioned that bilateral extraction of lower molars could shorten the mandibular ramal and condylar heights [17].

\section{Extraction of all mandibular and maxillary first permanent molars}

In general, where dental caries affects one more mandibular and 
maxillary first permanent molars, it becomes a significant problem affecting orthodontic decision-making. The mandibular molar should be considered for extraction (up to a year or two or even more, depending on the dental age of the patient) before eruption of the maxillary first molar. When it is decided that all first permanent molars are extracted, then the aim is to facilitate natural development of Class I occlusion of the second permanent molars which will take up the position of the already extracted first permanent molars.

\section{Other considerations}

Stage of dental development: if the patient is young, e.g., 6 or 7 years of age, then there will be at least 4 to 5 years before the second permanent molars are expected to erupt. Therefore, it is important to maintain the carious first permanent molars until the patient is at least 10 years old. Therefore, the critical age for considering first permanent molar extractions seems to be 7-10 years of age. Very early extraction of first permanent molar is usually followed by large anterior migration of the second permanent molars leading to reduced dental arch space, which will be worse if there is an already anterior crowding.

It is impractical to use space maintainers to prevent anterior migration of unerupted second molars, especially if it is heavily carious.

a) Asymmetrical extraction of first permanent molars: There are situations in which the clinician has to consider extracting first permanent molars asymmetrically. For instance, if more than one first molar has a large occlusal surface defect, or there is multiple twosurface caries involvement, the clinician must study the dentition and occlusion carefully to determine whether one or two molars should be kept. Sometimes diagonally opposing molars become grossly carious, (e.g., maxillary right molar and mandibular left molar). This asymmetrical effect may not be improved by keeping the other two molars, but to emphasize: taking account of timing for extracting the maxillary first permanent molars [18]. Also, effects of asymmetrical extractions should be considered with respect to anterior dental center line deviations. To conclude, in such cases the clinician should assess the total occlusion to decide how the extraction of a molar may help to overcome a malocclusion problem or make it worse.

b) Congenital absence of teeth: This can only be checked with radiograph and very likely complicates orthodontic decision-making. There would be a large open space if the first permanent molar was extracted when the second premolar was congenitally absent; therefore; the first molar, even if it is carious, should be kept if possible. It would be very difficult to close such large space even with fixed orthodontic appliances. Absence of third molar may also be a problem because it may not become visible in the radiographic X-ray until as late as 12 years of age or even later [19].

c) Position of unerupted second permanent molars: the second molar may be ectopically positioned, such as a mesio-angular impaction against the mandibular first molar. A decision must then be made about the prognosis for the eruption of the second molar if the first molar is extracted. It is difficult to make the prognosis, and thus no guaranteed rule can be suggested to help the decision about extraction.

There are three additional observations to be considered about uncontrolled second molar drift into mesial extraction space:

- Molar teeth will always tend to move mesially: The maxillary second permanent molars move mesially with slight tipping and mesial-to-palatal rotation; mandibular molars move mesially less than maxillary molars with variable mesial-to-lingual tipping.
- Maxillary second permanent molars will always move faster and longer distance than the mandibular molars.

- The earlier extraction age, particularly before 8 years of age, the greater the amount of mesial drifts of the second permanent molars [20].

c) Loss of vertical development following extractions of both mandibular first permanent molars: this is only likely to be a problem if there is already a skeletally short vertical dimension and associated with multiple losses of primary molars.

Note: with any form of treatment which a dentist (general practitioner, orthodontist, pedodontist, oral surgeon, periodontist) recommends e.g., extraction, there is the associated responsibility to consider the consequences of the recommendation. Thus the particular practitioner's involvement in patient care does not end with extraction of painful and pathologically affected teeth. Rather, he/she has a direct responsibility to advise the patient or parents of the predictive effects of any extraction on the benefit of the patient. If the practitioner cannot offer such a service, then it is better not to extract or recommend extraction.

There are special considerations when extracting permanent molar teeth, particularly mandibular molars and also premolars; to make sure that the alveolar socket walls, buccally and lingually, are retained in their normal positions and not allowed to collapse together. If the socket walls are compressed together (collapsed), or if a wall is fractured away and lost during the extraction, then the alveolar process at the extraction site will probably undergo atrophy. This atrophy will prevent any natural mesial migration of adjacent teeth, so that the extraction space will not close. Orthodontic closure of the extraction space will also be very difficult even with fixed appliances, requiring skeletal anchorage which might be of side effects e.g., displacement of soft tissues [21].

\section{References}

1. Albadri S, Zaitoun H, McDonnell ST, Davidson LE (2007) Extraction of first permanen molar teeth: results from three dental hospitals. Br Dent J 203: E14. [Crossref]

2. Jalevik, B. and M. Moller, (2007) Evaluation of spontaneous space closure and development of permanent dentition after extraction of hypomineralized permanent firs molars. International journal of paediatric dentistry, the British Paedodontic Society and the International Association of Dentistry for Children. 17: 328-35. [Crossref]

3. Hunter ML, Addy M, Dummer PM, Hunter B, Kingdon A, et al., (1991) A longitudina study of the condition of first permanent molars in a group of adolescents with special reference to elective orthodontic tooth extraction. Community dental health 8: 9-15. [Crossref]

4. Penchas J, Peretz B, Becker A (1994) The dilemma of treating severely decayed firs permanent molars in children: to restore or to extract. ASDC J Dent Child 61: 199-205. [Crossref]

5. Forss H Widstrom E (2003) The post-amalgam era: a selection of materials and their longevity in the primary and young permanent dentitions. International journal of paediatric dentistry / the British Paedodontic Society [and] the International Association of Dentistry for Children. 13: 158-64. [Crossref]

6. Gill DS, Lee RT, Tredwin CJ (2001) Treatment planning for the loss of first permanent molars. Dent Update 28: 304-308. [Crossref]

7. Yavuz I, , Bülent Baydaş, Ayşegül İkbal, İlhan Metin Dağsuyu, et al. (2006) Effects of early loss of permanent first molars on the development of third molars. American journal of orthodontics and dentofacial orthopaedics: Official publication of the American Association of Orthodontists, its constituent societies, and the American Board of Orthodontics. 1305: 634-638.

8. Bayram M, Ozer M, Arici S (2009) Effects of first molar extraction on third molar angulation and eruption space. Oral Surg Oral Med Oral Pathol Oral Radiol Endod 107: e14-20. [Crossref] 
9. Ay S, Uğur Ağar, A. Altuğ Bıçakçı, H. Hüseyin Köşger (2006) Changes in mandibular third molar angle and position after unilateral mandibular first molar extraction. American journal of orthodontics and dentofacial orthopedics: Official publication of the American Association of Orthodontists, its constituent societies, and the American Board of Orthodontics. 129: 36-41.

10. Rajashekhara BS, Keyur JM, Bhavna D, Poonacha KS (2012) Management of early loss of first permanent molar: a new technique. J Indian Soc Pedod Prev Dent 30: 349-351. [Crossref]

11. Nagasiri R, Chitmongkolsuk S (2005) Long-term survival of endodontically treated molars without crown coverage: a retrospective cohort study. J Prosthet Dent 93: 164170. [Crossref]

12. Strange DM, Seale NS, Nunn ME, Strange M (2001) Outcome of formocresol/ZOE sub-base pulpotomies utilizing alternative radiographic success criteria. Pediatr Dent 23: 331-336. [Crossref]

13. Barrieshi-Nusair KM, Qudeimat MA (2006) A prospective clinical study of mineral trioxide aggregate for partial pulpotomy in cariously exposed permanent teeth. $J$ Endod 32: 731-735. [Crossref]

14. Estrela C, Bammann LL, Estrela CR, Silva RS, Pécora JD (2000) Antimicrobial and chemical study of MTA, Portland cement, calcium hydroxide paste, Sealapex and Dycal. Braz Dent J 11: 3-9. [Crossref]

15. McDougal RA, Delano EO, Caplan D, Sigurdsson A, Trope M (2004) Success of an alternative for interim management of irreversible pulpitis. J Am Dent Assoc 135: 1707 1712. [Crossref]

16. Mandari GJ, FJ van't Hof MA (2003) Six-year success rates of occlusal amalgam and glass-ionomer restorations placed using three minimal intervention approaches. Caries Res 37: 8. [Crossref]

17. Halicioglu K, Celikoglu M, Caglaroglu M, Buyuk SK, Akkas I, et al. (2013) Effects of early bilateral mandibular first molar extraction on condylar and ramal vertical asymmetry. Clin Oral Investig 17: 1557-1561. [Crossref]

18. Sandler PJ, Atkinson R, Murray AM (2000) For four sixes. American journal of orthodontics and dentofacial orthopedics: Official publication of the American Association of Orthodontists, its constituent societies, and the American Board of Orthodontics. 117: 418-34

19. Zandi M, Shokri A, Malekzadeh H, Amini P, Shafiey P (2015) Evaluation of third molar development and its relation to chronological age: a panoramic radiographic study. Oral Maxillofac Surg 19: 183-189. [Crossref]

20. Ong DC, Bleakley JE (2010) Compromised first permanent molars: an orthodontic perspective. Aust Dent J 55: 2-14. [Crossref]

21. Jacobs C, Müller CJ, Luley C, Erbe C, Wehrbein H (2011) Orthodontic space closure after first molar extraction without skeletal anchorage. Journal of orofacial orthopaedics-Fortschritte der Kieferorthopadie: Organ/official journal Deutsche Gesellschaft fur Kieferorthopadie. 72: 51-60.

Copyright: (C2015 Elsheikh M. This is an open-access article distributed under the terms of the Creative Commons Attribution License, which permits unrestricted use, distribution, and reproduction in any medium, provided the original author and source are credited. 